\title{
Study of Unbiased Plotting Position Formulae for the Generalized Extreme Value (GEV) Distribution
}

\author{
Itolima Ologhadien
}

\begin{abstract}
The determination of appropriate quantile relations between the magnitude of extreme events and the corresponding exceedance probabilities is a prerequisite for optimum design of hydraulic structures. Various plotting position formulae have been proposed for estimating the exceedance probabilities or recurrence in. In this study, eight plotting position formulae recommended for GEV distribution were used for estimating the exceedance probabilities of annual maximum series of River Niger at Baro, Kouroussa and Shintaku hydrological stations. The performance measures of PPCC, RRMSE, PBIAS, MAE and NSE were calculated by applying their individual equations to each pair of observed AMS, arranged in ascending order, and exceedance probabilities calculated using each plotting positions. The result of the study show that Weibull was the best plotting position formula, seconded by Beard and thirdly, In - na and Ngugen. This study underscores the necessity to accurately size water infrastructure. In a recent paper, the author found GEV distribution the best - fit probability distribution model in Nigeria. Thus, the need to develop indepth understanding and accurate estimation of exceedance probabilities and return periods using the GEV distribution. Furthermore, this paper recommends similar studies to be conducted for Pearson Type 3(PR3) and Log Pearson Type 3 (LP3) distributions.
\end{abstract}

Index Terms - Plotting positions, exceedance probability, performance measures, quantile relations, and GEV distribution.

\section{INTRODUCTION}

Probability plotting positions are used for graphical evaluation of probability distribution models and they also serve to relate the magnitude of an event to its corresponding probability of exceedance (or non-exceedance) amongst others. Because of their attractive characteristics, they are widely used in water resource engineering practice. To date, more than ten plotting position formulae have been proposed may be cited in the following literature [1]-[15]. A brief review of the cited literature show that the various plotting position formulae differ and with diverse claims by researchers. [16] provided a succinct review and discussions on Plotting Position formulae and observed that the choice of a plotting position formulae should depend on the use, which is to be made of the results, and may also depends on the underlying distribution. Furthermore, [16] pointed out that much confusion and disagreement concerning the choice of plotting positions is probably due to the fact CDF of the reduced variate is not equal to the expected value of the CDF. For example, [13] stated that "if a single simple distribution free formula were required then, Cunnane would be the best compromise" This conclusion has been found acceptable to many hydrologists according to [5]. Conversely, [17] reported that in estimating the return periods there is only one correct plotting position, which is weibull plotting position formula.

[18] rejected the claims of [13] and emphasized that Weibull formula should be used as a unique plotting position formula. Furthermore [17] recommended that all distributions dependent plotting formulae should be abandoned in favour of Weibull. Notwithstanding the critique of [17], the Cunnane formula is recommended by Environment Canada as the default plotting position option. While Gringorten plotting position is standard for New Zealand according to [19]. Also [13] recommended that a plotting position formula should be unbiased and should have the smallest mean square error among the other among other mathematical criteria. Furthermore [19] proposed that plotting positions should be examined in greater details and advocated collaboration with other researchers in finding the best plotting position formula for flood frequency analysis. Also [20] observed that the exiting practice in the selection of a particular formula is arbitrary and often gives unrealistic results. Generally, there is a wide in quantile estimates when particular events are computed with different plotting positions. Thus, the need for this study in determining the best plotting position formula for GEV distribution. The evaluation of unbiased plotting is still a growing research area in hydraulic and water resources engineering. In a recent study on comparative evaluation of probability distribution models of flood flow on Niger/Benue basins in Nigeria. It was found that the best-fit distribution in both Niger/Benue basins are GEV, PR3 and LP3. Since different plotting positions results in different quintile estimates for different distributions. In this study, eight unbiased plotting position formulae recommended for GEV distribution are evaluated to find the best for GEV distribution. The selection of the most suitable plotting position was made based on PPCC, PBIAS and RRMSE, MAE and NSE indices. The parameters of GEV distribution were estimated using probability weighting moments and L-Moments. 


\section{A. Study Area}

The data of three hydrological stations on the Niger river basin at Baro, Kourassou and Shintaku were employed in this study. The stations and their geographic attributes and descriptive statistics are shown in Table I. The Niger River basin covers a total area of approximately 2,156,000 $\mathrm{km}^{2}$, only about $1,270,000 \mathrm{~km}^{2}$ actively contribute to runoff and river discharge. The whole basin is spread over the territory ten countries. Table I shows the study stations along the Niger River. The coefficient of variation shows that the flow is moderately variable. Secondly, the annual maximum discharges are generally skewed and for this reason, normal distribution will not be a suitable model.

TABLE I: GEOGRAPHIC CHARACTERISTICS AND DESCRIPTIVE STATISTIC

\begin{tabular}{cccc}
\hline \multirow{2}{*}{ Parameter } & \multicolumn{3}{c}{ Hydrological Stations } \\
\cline { 2 - 4 } & Baro & Kourassou & Shintaku \\
\hline Latitude & $08^{\circ} 35^{\prime}$ & $08^{\circ} 51^{\prime}$ & $07^{\circ} 10^{\prime}$ \\
Longitude & $08^{\circ} 23^{\prime}$ & $10^{\circ} 47^{\prime}$ & $06^{\circ} 45^{\prime}$ \\
Minimum Flow & $423 \mathrm{~m}^{3} / \mathrm{sec}$ & $275 \mathrm{~m}^{3} / \mathrm{sec}$ & $7730.59 \mathrm{~m}^{3} / \mathrm{sec}$ \\
Maximum Flow & $1150 \mathrm{~m}^{3} / \mathrm{sec}$ & $1185 \mathrm{~m}^{3} / \mathrm{sec}$ & $16480 \mathrm{~m}^{3} / \mathrm{sec}$ \\
Mean Flow & $716.34 \mathrm{~m}^{3} / \mathrm{sec}$ & $713.98 \mathrm{~m}^{3} / \mathrm{sec}$ & $13,320.8 \mathrm{~m}^{3} / \mathrm{sec}$ \\
Standard & $188.71 \mathrm{~m}^{3} / \mathrm{sec}$ & 223.643 & $2015.43 \mathrm{~m}^{3} / \mathrm{sec}$ \\
Deviation & & $\mathrm{m}^{3} / \mathrm{sec}$ & \\
Coefficient of & 0.264 & 0.313 & 0.151 \\
Variation & 0.122 & 0.242 & -0.671 \\
Skewness & $1948-2000$ & $1950-2000$ & $1957-2014$ \\
Data length & $(53$ years $)$ & $(51$ years) & $(58$ years) \\
\hline
\end{tabular}

\section{METHODOLOGY}

\section{A. Method of Moments (MOM)}

\section{Probability Weighted Moments/L-Moments}

The L-Moments are easily calculated in terms of probability weighted moments. Sample probability weighted moments, computed from data values $\mathrm{Q}_{1: \mathrm{n}}, \mathrm{Q}_{2: \mathrm{n}}, \ldots \mathrm{Q}_{\mathrm{n}: \mathrm{n}}$, arranged in ascending order, are given by [21]:

$$
\begin{aligned}
& b_{o}=n^{-1} \sum_{j=1}^{n} Q: n j \\
& b_{r}=n^{-1} \sum_{j=r+1}^{n} \frac{(j-1)(j-2) \ldots .(j-r)}{(n-1)(n-2) \ldots . .(n-r)} Q_{j: n}
\end{aligned}
$$

The probability weighted moments, $\mathrm{b}$, are estimated for a given gauge record using:

$b_{o}=\frac{1}{N} \sum_{i=1}^{n} Q_{i}$ (i.e., the sample mean)

$b_{1}=\frac{1}{N} \sum_{i=1}^{n} \frac{(i-1)}{(N-1)} Q_{i}$

$b_{2}=\frac{1}{N} \sum_{i=1}^{n} \frac{(i-1)(i-2)}{(N-1)(N-2)} Q_{i}$

$b_{3}=\frac{1}{N} \sum_{i=1}^{n} \frac{(i-1)(i-2)(i-3)}{(N-1)(N-2)(N-3)} Q_{i}$ where $Q_{i}$ is the ith element of annual maximum flows arranged in ascending order; and $\mathrm{N}$ is the sample size (i.e., the number of annual maxima in the record).

L-moments are defined in terms of probability weighted moments, analogously to the sample L-moments:

$\lambda_{1}=b_{0}$

$\lambda_{2}=2 b_{1}-b_{0}$

$\lambda_{3}=6 b_{2}-6 b_{1}+b_{0}$

$\lambda_{4}=20 b_{1}-30 b_{2}+12 b_{0}-b_{0}$

L-moments ratio are defined by:

$$
\tau=\lambda_{1} \lambda_{2}
$$

The $4 \mathrm{~L}$-Moments $\left(\lambda_{1}, \lambda_{2}, \lambda_{3}\right.$ and $\left.\lambda_{4}\right)$ were derived using the 4 PWMS. The procedure for fitting GEV distribution using the PMW method are: i) arrange the observed annual maximum series in ascending order, ii) Calculate the $4 \mathrm{~L}$ Moments $\left(\lambda_{1}, \lambda_{2}, \lambda_{3}\right.$ and $\left.\lambda_{4}\right)$, iii) Calculate the 4 PWMs $\left(b_{0}, b_{1}\right.$, $\mathrm{b}_{2}$ and $\left.\mathrm{b}_{3}\right)$, iv) Calculate the three parameters: location $(\zeta)$, scale $(\alpha)$, and shape $(\mathrm{k})$. Using a specified recurrence interval, fit all the parameters to the quantile relations and estimate the magnitudes.

The useful rates are:

$$
\tau=\lambda
$$

The L-moments ratios are $\mathrm{L}-\mathrm{cv}\left(\tau_{2}\right)$, L-Skewness $\left(\tau_{3}\right)$ and L-Kurtoses $\left(\tau_{4}\right)$, and defined as:

$\mathrm{L}-\mathrm{CV}=\tau_{2}=\frac{\lambda_{2}}{\lambda_{1}}$

$\mathrm{L}-$ Skewness $=\tau_{3}=\frac{\lambda_{3}}{\lambda_{2}}$

$\mathrm{L}-$ kurtosis $=\tau_{4}=\frac{\lambda_{4}}{\lambda_{3}}$

\section{Generalized Extreme Values (GEV) Distribution}

The GEV distribution is a three - parameter distribution, thus it can be described by three parameters: location $(\zeta)$, scale $(\alpha)$, and shape $(\mathrm{k})$. The shape parameter describes the tail of the distribution and influences the estimates of higher return periods. Depending on the estimated value of $\mathrm{k}$, the fitted distributed converges to one of three distinct distributions as follows: Type1/Gumbel (EV1) if $\mathrm{k}=0$, when $\mathrm{k}>0$, then TypeII/Frechet $(\mathrm{EV} 2)$ and when $\mathrm{k}<0$, Type III/Weibull (EV3) [22].

The scale parameter defines where the bulk of the distribution has and the shape parameter which affect the shape of the distribution and governs the tail of each distribution. When the sample size is bigger ( say $\mathrm{N}>50$ ), the GEV distribution shows a better overall. The probability distribution function (PDF) and cumulative distribution function (CDF) of the GEV distribution are respectively given in (8) and (9): 
$\mathrm{f}(\mathrm{Q})-\frac{1}{\alpha}\left[1-K\left(\frac{Q-\beta}{\alpha}\right)\right]^{1 / K-1} \exp \left\{-\left[I-K\left(\frac{Q-\beta}{\alpha}\right)\right]^{1 / K-1}\right\}$

$\mathrm{F}(\mathrm{Q})-\exp \left\{-\left[I-K\left(\frac{Q-\beta}{\alpha}\right)\right]^{1 / K}\right\}$

where $\mathrm{k}, \alpha$ and $\beta$ are respectively shape, scale, and location parameters performance [23].

The parameters of GEV distribution are define according to [12] as:

$\mathrm{k}=7.8590 \mathrm{c}+2.9554 \mathrm{c}^{2}$

$\alpha=\frac{\lambda_{2} k}{(1-2-k) \Gamma(1+k)}$

$\xi=\lambda_{1} \frac{\alpha}{k}\{1-\Gamma(1+k)\}$

$C=\frac{2}{3+\tau_{3}}-\frac{\log 2}{\log 3}$

where $\Gamma$ is a gamma function.

The calculation proceeds first with the calculation of the parameter "c" in Equation 11 using the L-skewness estimator $\tau_{3}$, then the shape parameter, $\mathrm{k}$ using (8), followed by the scale parameter, $\alpha$, according to (9). Finally, the estimate of the location parameter, $\xi$, using (10), and sample mean $\bar{Q}$ given by $\lambda_{1}\left(\right.$ or $\left.b_{0}\right)$. Once all parameters have been estimated, the T-year return flood is calculated as in (12) [24]:

$Q_{T}=\zeta+\left\{\frac{\alpha}{k}\right\}\left[1-\left(-\log \left(\frac{T-1}{T}\right)\right)^{K}\right]$

\section{B. Ploting Position Formulae}

The plotting position formulae used in the study may be represented by:

$\mathrm{P}=\left(\mathrm{Q} \leq \mathrm{q}_{\mathrm{i}}\right)=\frac{i-b}{N+1-2 b}$

(13) expresses the probability of non-exceedance or the cumulative probability of non-exceedance. The values of "b" varies from 0 to 0.5 . For example, when $b=0.44$. Equation 15 is called Gringorten Plotting, different position formulae are obtained by changing the values of " $b$ " and so on, Table II shows the selected plotting position formulae.
TABLE II: PLOTTING POSITION FORMULAS

\begin{tabular}{|c|c|c|c|}
\hline $\mathrm{S} / \mathrm{N}$ & Class & Plotting Position Formula (PPF) & $\begin{array}{l}\text { Recommended } \\
\text { Probability } \\
\text { Distribution } \\
\end{array}$ \\
\hline 1. & $\begin{array}{l}\text { Gringorten } \\
\quad(1963)\end{array}$ & $\mathrm{P}_{\mathrm{i}}=\frac{i-0.44}{N+0.12}$ & $\begin{array}{c}\text { Gumbel, } \\
\text { Weibull, GEV }\end{array}$ \\
\hline 2. & $\begin{array}{l}\text { Cunnane } \\
(1978)\end{array}$ & $\mathrm{P}_{\mathrm{i}}=\frac{i-0.4}{N+0.2}$ & $\begin{array}{l}\text { GEV, } \log - \\
\text { Gumbel, PR3 } \\
\text { LP3 }\end{array}$ \\
\hline 3. & $\begin{array}{l}\text { In }- \text { na } \\
\text { and } \\
\text { Nguyen } \\
(1989)\end{array}$ & $\mathrm{P}_{\mathrm{i}}=\frac{N-i+0.05 C s+0.65}{N-0.08 C s+0.38}$ & GEV \\
\hline 4. & $\begin{array}{l}\text { Goel and } \\
\text { De (1993) }\end{array}$ & $\mathrm{P}_{\mathrm{i}}=\frac{i-0.02 C s-0.32}{N-0.04 C s+0.36}$ & GEV \\
\hline 5. & $\begin{array}{l}\text { Kim et al. } \\
\text { (2012) }\end{array}$ & $\begin{array}{c}\mathrm{P}_{\mathrm{i}}= \\
i-0.3200 \\
N+0.0149 C s^{2}-0.1364 C s+0.3225\end{array}$ & GEV \\
\hline 6. & $\begin{array}{l}\text { Weibull } \\
\text { (1939) }\end{array}$ & $\frac{i}{N+1}$ & $\begin{array}{c}\text { All } \\
\text { Distributions }\end{array}$ \\
\hline 7. & $\begin{array}{l}\text { Beard } \\
(1945)\end{array}$ & $\frac{i-0.3175}{N+0.365}$ & $\begin{array}{c}\text { All } \\
\text { Distributions }\end{array}$ \\
\hline 8. & $\begin{array}{l}\text { Hosking } \\
(1990)\end{array}$ & $\mathrm{P}_{\mathrm{i}}=\frac{i-0.35}{N}$ & $\begin{array}{l}\text { Some 3- } \\
\text { parameter } \\
\text { Distribution }\end{array}$ \\
\hline
\end{tabular}

\section{Performance Measure}

1. Probability Plot Correlation Coefficient Test

The probability plot correlation coefficient (PPCC) test is one of the goodness - of - fit tests for determining a suitable probability distribution for a sample. The PPCC test determines whether an assumed probability distributions are acceptable for the sample data using the correlation coefficients between the sample data and theoretical quantiles of assumed probability distribution [8]. [25] reported that PPCC test provides a conceptual simple attractive, and powerful alternative to other possible hypothesis tests. The PPCC test statistics is formulated on the basis of the linear correlation coefficient $r$ between the data ranked in ascending order, denoted by $\mathrm{Q}_{\mathrm{i}}$ and the theoretical quantiles $\mathrm{W}_{\mathrm{i}}$, which is calculated as $\mathrm{Wm}=\Phi^{-1}\left(\mathrm{P}_{\mathrm{i}}\right)$ of the normal distribution. The inverse function $\Phi^{-1}\left(\mathrm{P}_{\mathrm{i}}\right)$ is calculated brought the MS Excel built-in function NORM-INV $\left(\mathrm{P}_{\mathrm{i}}, \bar{Q} ; \sigma\right)$, which returns corresponding $\mathrm{W}_{\mathrm{i}}$ values with $\bar{Q}$; and $\sigma$ the mean and standard deviation of the observed data series. The PPCC test statistics is calculated as:

$r=\frac{\sum_{i=1}^{n}\left(Q_{i}-\bar{Q}\right)\left(W_{i}-\bar{W}\right)}{\sqrt{\sum_{m=1}^{N}\left(Q_{i}-\bar{Q}\right)^{2} *\left(W_{i}-\bar{W}\right)^{2}}}$

where $\bar{Q}=\frac{1}{N} \sum_{i=1}^{N} Q$ and $\bar{W}=\sum_{i=1}^{N} W_{i}$. In the alternative the value of $r$ in (16), may be observed through MS Excel built in function CORREL.

The 5\% critical value of PPCC Statistic of the GEV distribution can be approximated according to [17]: 
$\ln \left(\frac{1}{1-r_{c r i, \alpha}}\right)=\left(a_{1}+a_{2} \beta+a_{3} \beta^{2}+a_{4} \beta^{3}\right) \times N_{5}^{\left(\alpha_{6}+\alpha_{6} \beta+\alpha_{7} \beta 2\right)}$

For $\alpha=0.05,-0.20 \leq \beta \leq 0.25$ or $3.5351 \geq \mathrm{Cv}>0.0872$, the regression constant in (15) are $\mathrm{a}_{1}=1.6407 ; \mathrm{a}_{2}=0.0912$, $\mathrm{a}_{3}=1.7126, \mathrm{a}_{4}=-6.1241, \mathrm{a}_{5}=0.1806, \mathrm{a}_{6}=0.2557$, and $\mathrm{a}_{7}=-$ 0.5414. $\beta$ and $C V$ are shape factor and coefficient of variation respectively. The critical region for $\mathrm{Ho}$, at the significance level of $\alpha$, begin at $r_{\text {crit, } \alpha}$ below which, if $r<r_{\text {crit, } \alpha}$ the hypothesized GEV distribution is rejected.

The relative root-mean square error (RRMSE) computes the relative error between the observed and simulated values. The RRMSE statistics calculates each error in proportion to the size of the overall fit. Other statistical error indices used in this study are percent bias (PBIAS), maximum absolute error (MAE), and Nash-Sutclife efficiency (NSE). Details about the selected may be found in [26]. They are calculated as shown in (18)-(21).

$$
R R M S E=\sqrt{\frac{1}{N} \sum_{i=1}^{n}\left(\frac{Q_{i}-P_{i}}{Q_{i}}\right)^{2}}
$$

where $Q_{i}$ is ordered set of observation value and $P_{i}$ is predicted values for given values of $\mathrm{Q}_{\mathrm{i}}$.

$$
\begin{aligned}
& \text { PBIAS }=\left[\begin{array}{l}
\sum_{i=1}^{N}\left(Q_{i}-P_{i}\right) \\
\sum_{i=1}^{n} Q
\end{array} 100\right] \\
& N S E=1-\frac{\sum_{i=1}^{N}\left(Q_{i}-P_{i}\right)^{2}}{\sum_{i=1}^{N}\left(Q_{i}-\bar{Q}_{i}\right)^{2}} \cdot-\infty \leq \mathrm{NSE} \leq 1.0 \\
& \mathrm{MAE}=\frac{1}{N} \sum_{i=1}^{N}\left|Q_{i}-P_{i}\right|-\infty \leq \mathrm{MAE} \leq 1.0
\end{aligned}
$$

\section{RESULTS AND DISCUSSION}

Once the GEV probability model and parameters have been estimated using the methods of probability weighted moments, the flood quantile for any exceedance probability were derived in the form of (12). Table III shows the quantile recurrence interval $\left(\mathrm{Q}_{\mathrm{T}} \mathrm{T}\right)$ models of the study stations.

TABLE III: QUANTILE RELATIONS FOR THE STUDY STATIONS

\begin{tabular}{ccc}
\hline Station & $\mathrm{Q}_{\mathrm{T}}-\mathrm{T}$ Model \\
\hline Baro & $\mathrm{Q}_{\mathrm{T}}=645.97+746.29 *\left\{1-\left(-\mathrm{LN}\left\{1-\left(-L N\left(1-\frac{1}{T}\right)\right)^{0.25343}\right\}\right.\right.$ \\
$\mathrm{Q}_{\mathrm{T}}=623.48+1195.05 *\{1-(-\mathrm{LN}$ & \\
Kourassou & $\left\{1-\left(-L N\left(1-\frac{1}{T}\right)\right)^{0.1786}\right\}$ \\
$\mathrm{Q}_{\mathrm{T}}=$ & $12875.51+4015.57 *\{1-(-\mathrm{LN}$ \\
Shintaku & $\left.\left\{1-\left(-L N\left(1-\frac{1}{T}\right)\right)\right)^{0.5532}\right\}$
\end{tabular}

The eight plotting position formulae in Table II were compared for Generalized Extreme Value distribution by computing the quantile discharges using the eight plotting position formulae, then comparing each simulated discharges with the corresponding observed discharges. The plotting position formulae were evaluated using the following goodness-of-fit criteria: PPCC, PBIAS, NSE and MAE. Based on the computed statistical tests, a ranking scheme is adopted to rank all the eight plotting position formulae.

Ranking scores are assigned to each plotting position formulae according to the optimal value of the test statistic. For example, a plotting position formula with MAE, RMSE, and PBIAS values, of zero and NSE value of 1.0 is scored 1. In case of a tie, equal scores are given to the contending plotting position formulae. Finally, for each plotting position formula, the total score is obtained by summing the individual scores across the goodness-of-fit tests.

Tables IV-VI presents the ranking of plotting position formulae for Baro, Kourassou and Shintaku respectively. According to ranking scheme adopted, the plotting position with the least total score is adjudged the best for the station. For Baro, the best formula is Beard, seconded by Weibull, thirdly - In-na and Ngugen and Goel and De. For Kourassou; Weilbull is the best, seconded by Beard and thirdly In-na and Ngugen and Goel and De. Finally, at Shintaku, Weibull is the best, seconded by Cunnane and Beard and thirdly, Gringorten and Goel and De.

The total scores for each station were summed across the 3 study stations and the resulting plots are presented in Fig. 14. Fig. 4 shows the overall ranking of the plotting position with Weibull, was adjudged the best, seconded by Beard and thirdly by Goel and De. The impetus for this research is GEV was found the best probability distribution model for Nigeria and the study was undertaken to find the best probability plotting position for the GEV distribution. The PWM was used for estimation of GEV distribution parameters, following the recommendation of [27]. The findings of the study agrees with [9] who found Weibull the best plotting position for Puducherry, South India, but disagree with [5] who suggested that if an unbiased plotting position formula were required for the GEV, the Gringorten or Cunnane formula would be the best selection. Furthermore [17] and [18] recommended that all distribution dependent "plotting position" formula should be abandoned in favour of Weibull [15] formula, and it should be used as the unique plotting position.

\section{RECOMMENDATION FOR FURTHER RESEARCH}

Further studies are required to evaluate the recommended plotting position formulae to determine the best plotting positions formula for Pearson Type III and Log Pearson Type III distributions. These two distributions have also been found to model the distribution of annual floods in Nigeria. 
TABLE IV: RANKING OF PLOTTING POSITION FORMULAE FOR BARO

\begin{tabular}{|c|c|c|c|c|c|c|c|c|}
\hline \multirow{2}{*}{ PPF } & \multicolumn{5}{|c|}{ Computed Performance Measures } & \multicolumn{3}{|c|}{ PPCC Statistics } \\
\hline & MAE & NSE & PBIAS & RMSE & TOTAL & PPCC & $\mathrm{PPC}_{\text {crit }}$ & Decision \\
\hline Cunnane & 5 & 6 & 3 & 6 & 20 & 0.982 & 0.987 & Reject \\
\hline Weibull & 4 & 1 & 5 & 1 & 11 & 0.996 & 0.987 & Reject \\
\hline Gringorten & 7 & 6 & 4 & 7 & 24 & 0.982 & 0.987 & Reject \\
\hline Beard & 2 & 3 & 2 & 3 & 10 & 0.983 & 0.987 & Reject \\
\hline IN-NA \& Ngugea & 1 & 2 & 7 & 2 & 12 & 0.981 & 0.987 & Reject \\
\hline Geol \& De & 3 & 4 & 1 & 4 & 12 & 0.984 & 0.987 & Reject \\
\hline Kim et al. & 6 & 4 & 6 & 5 & 21 & 0.980 & 0.987 & Reject \\
\hline Hosking & 8 & 6 & 8 & 8 & 22 & 0.985 & 0.987 & Reject \\
\hline *Range: & 0.0 to $\infty$ & $-\infty$ to 1.0 & $-\infty$ to $\infty$ & 0.0 to $\infty$ & & & & \\
\hline *Optimal Value: & 0.0 & 1.0 & 0.0 & 0.0 & & & & \\
\hline
\end{tabular}
$*[26]$

TABLE V: RANKING OF PLOTTING POSITION FORMULAE FOR KOUROUSSU

\begin{tabular}{|c|c|c|c|c|c|c|c|c|}
\hline \multirow{2}{*}{ PPF } & \multicolumn{5}{|c|}{ Computed Performance Measures } & \multicolumn{3}{|c|}{ PPCC Statistics } \\
\hline & MAE & NSE & PBIAS & RMSE & TOTAL & PPCC & $\mathrm{PPC}_{\text {crit }}$ & Decision \\
\hline Cunnane & 6 & 6 & 5 & 7 & 24 & 0.992 & 0.887 & Reject \\
\hline Weibull & 2 & 1 & 1 & 1 & 5 & 0.998 & 0.887 & Reject \\
\hline Gringorten & 7 & 7 & 7 & 8 & 29 & 0.993 & 0.887 & Reject \\
\hline Beard & 1 & 2 & 1 & 2 & 6 & 0.994 & 0.887 & Reject \\
\hline IN-NA \& Ngugea & 3 & 4 & 2 & 4 & 13 & 0.986 & 0.887 & Reject \\
\hline Geol \& De & 4 & 3 & 3 & 3 & 13 & 0.988 & 0.887 & Reject \\
\hline Kim et al. & 5 & 5 & 4 & 6 & 20 & 0.985 & 0.887 & Reject \\
\hline Hosking & 8 & 8 & 6 & 5 & 27 & 0.989 & 0.887 & Reject \\
\hline Range: & 0.0 to $\infty$ & $-\infty$ to 1.0 & $-\infty$ to $\infty$ & 0.0 to $\infty$ & & & & \\
\hline Optimal Value: & 0.0 & 1.0 & 0.0 & 0.0 & & & & \\
\hline
\end{tabular}

$*[26]$.

TABLE VI: RANKING OF PLOTTING POSITION FORMULAE FOR SHINTAKU

\begin{tabular}{|c|c|c|c|c|c|c|c|c|}
\hline \multirow{2}{*}{ PPF } & \multicolumn{5}{|c|}{ Computed Performance Measures } & \multicolumn{3}{|c|}{ PPCC Statistics } \\
\hline & MAE & NSE & PBIAS & RMSE & TOTAL & PPCC & PPC $_{\text {crit }}$ & Decision \\
\hline Cunnane & 3 & 1 & 2 & 4 & 10 & 0.979 & 0.892 & Reject \\
\hline Weibull & 1 & 3 & 3 & 1 & 8 & 0.997 & 0.882 & Reject \\
\hline Gringorten & 6 & 2 & 1 & 5 & 14 & 0.979 & 0.892 & Reject \\
\hline Beard & 2 & 2 & 4 & 2 & 10 & 0.979 & 0.882 & Reject \\
\hline IN-NA \& Ngugea & 7 & 2 & 8 & 7 & 24 & 0.978 & 0.892 & Reject \\
\hline Geol \& De & 4 & 2 & 5 & 3 & 14 & 0.979 & 0.892 & Reject \\
\hline Kim et al. & 8 & 2 & 6 & 8 & 24 & 0.979 & 0.892 & Reject \\
\hline Hosking & 5 & 2 & 7 & 6 & 20 & 0.975 & 0.892 & Reject \\
\hline *Range: & 0.0 to $\infty$ & $-\infty$ to 1.0 & $-\infty$ to $\infty$ & 0.0 to $\infty$ & & & & \\
\hline *Optimal Value: & 0.0 & 1.0 & 0.0 & 0.0 & & & & \\
\hline
\end{tabular}

$*[26]$.

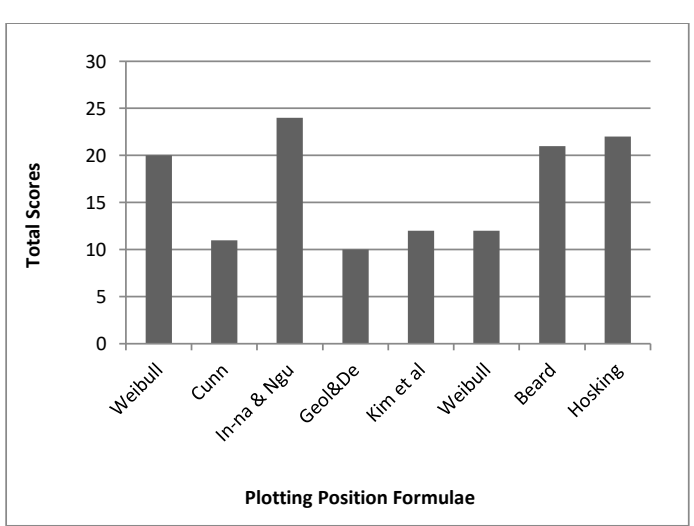

Fig. 1. Ranking of Plotting Position Formulae at Baro.

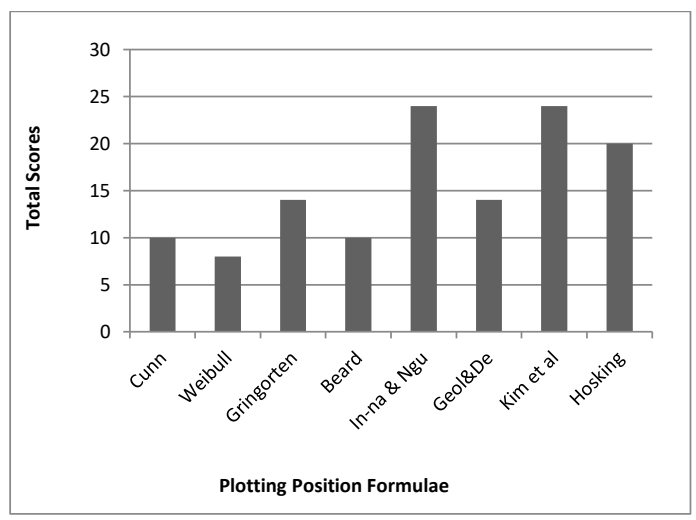

Fig. 3. Ranking of Plotting Position Formulae at Shintaku.

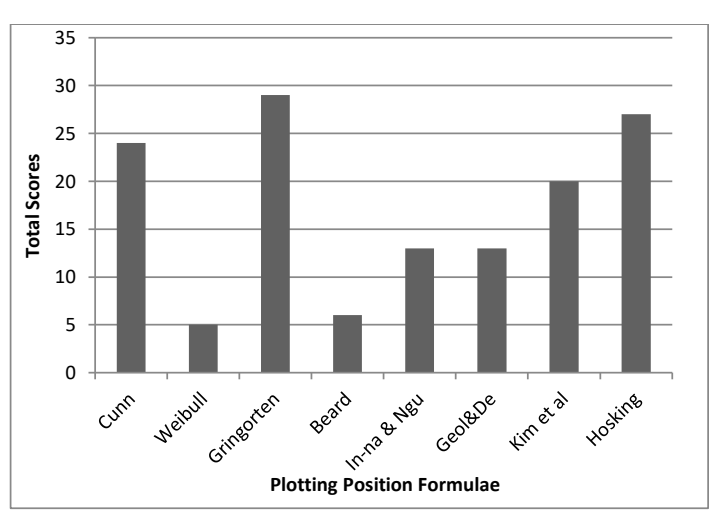

Fig. 2. Ranking of Plotting Position Formulae at Kouroussa.

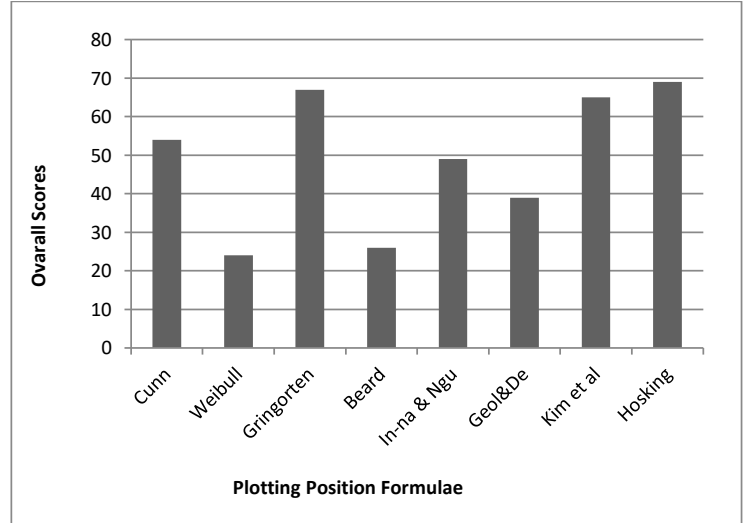

Fig. 4. Overall Ranking of Plotting Position Formulae. 


\section{CONCLUSION}

Based on the results of eight plotting position formulae recommended for GEV distribution, and the performance measures of PPCC, RRMSE, PBIAS, MAE and NSE. This study found Weibull plotting position formula the best for estimation of exceedance probabilities of annual maximum series of River Niger at Baro, Kouroussa and Shintaku hydrological stations.

\section{REFERENCES}

[1] Beard, L.R., 1943. Statistical analysis in hydrology. Trans. Am. Soc. Cir. Eng., 108: 1110-1160.

[2] Blom, G. (1958). Statistical estimates and transformed beta variables. John Wiley and Sons, New York.

[3] Gringorten, I.I. (1963). "A plotting rule for extreme probability paper.” Journal of Geophysical Research, Vol.68, No. 3, pp. 813-814.

[4] Hirsch, R.M. and Stedinger, J.R., 1987. Plotting positions for historical floods and their precision. Water Resour. Res., 23(4): 715727.

[5] Guo, S.L. (1990a). "A discussion on unbiased plotting positions for the general extreme value distribution." Journal of Hydrology, Vol. 121 , pp. 33-44.

[6] Shabri, A. (2002). "A comparison of plotting position formulas for the Pearson Type III distribution”, Journal Teknologi, 36@, Jun. 2002: 61 - 74, Universiti Teknologi Malaysia.

[7] In-na, N., and Nguyen, V-T-V. (1989). "An unbiased plotting position formula for the generalized extreme value distribution." Journal of Hydrology, Vol. 106, pp. 193-209.

[8] Ahn, H., Shin, H., Kim, S., and Heo, J-H. (2020) Comparison on Probability Plot Correlation Coefficient Test Considering Skewness of Sample for the GEV Distribution J. Korea Water Resources Association, Vol. 47, No. 2:161-170, http://dx.doi.org/10.3741/JKWRA.2014 .47.2.161 pISSN 1226-6280 eISSN 2287-6138.

[9] Murugappan, A. Sivaprakasam, S. and Mohan, S. (2017) "Ranking of Plotting Position Formulae in Frequency Analysis of Annual and Seasonal Rainfall at Puducherry, South India”. Global Journal of Engineering Science and Researches, 4(7), 67-76. ISSN 2348-8034.

[10] Stedinger, J.R., Vogel, R.M., Foufoula-Georgiou, E. (1993). Frequency analysis of extreme events. Handbook of Hydrology, D.R. Maidment, de., McGraw-Hill, New York, N.Y.,pp. 18.24-18.26.

[11] Kim, S., Shin, H., Joo, K., and Heo, J.-H. (2012). "Development of plotting position for the general extreme value distribution." Journal of Hydrology, Vol. 475, pp. 259-269.

[12] Hosking, J. R. M. and Wallis, J. R. Regional frequency analysis: An approach based on L-moments. 2005. Cambridge: Cambridge University Press.

[13] Cunnane, C. (1978). "Unbiased plottoing posiions-A review." Journal of Hydrology, Vol. 37, No. 3/4, pp. 205-222.

[14] Goel, N.K., and De, M. (1993). "Development of unbiased plotting position formula for General Extreme Value distribution." Stochastic Environmental Research and Risk Assessment, Vol. 7, pp. 1-13.

[15] Weibull, W., 1939. A statistical theory of strength of materials. Ing. Vet. Akad. Handl., No. 151, Generalstabens Litografiska An tals Forlag, Stockholm.

[16] Harter, H.L., 1984. Another look at plotting positions. Commun. Star., Theory and Methods, Vol.13(13): 1613-1633.

[17] Makkonen, L. (2006). "Plotting Positions in Extreme Value Analysis" Journal od Appl. Meteorol. and Climatol., 45, pp. 334 - 340.

[18] Makkonen, L., Pajari, M. and Tikanmaki, M (2013). Discussion on "Plotting positions for fitting distributions and Exreme Value Analysis". Canadian. J. Civ. Eng. 40: 927-929.

[19] Connell, R.J. and Mohessen(2015) " Estimation of plotting position for flood frequency analysis, HWRS, pp. 1-9. https://www.researchgate.net/publication/309177974.

[20] [20] Alam, M.J.B., and Matin, A. (2005) "Study of Plotting Position Formulae for Surma Basin in Bangladesh" Journal of Civil Engineering, 33(1), 9-17.

[21] Chadwick, A., Morfett, J., and Borthwick, M. (2004). Hydraulics in Civil and Environmental Engineering, $4^{\text {th }}$ Edition, ISBN O -415 39236-5.

[22] Lutz, J., Grinde, L., and Dyrrdal, A.V (2020). "Estimating Rainfall Design Values for the City of Oslo, Norway - Comparison of methods and Quantification of Uncertainty. Water 2020, 12, 1735; doi: $10.3390 / w 12061735$.

[23] Cunnane, C., (1989). Statistical Distribution for Flood Frequency Analysis. Operational Hydrol. Rep. 33, World Meteorological Organisation, Geneva.

[24] Millington, N., Das, S., and Simonovic S. P. (2011) "The Comparison of GEV, Log - Pearson Type 3 and Gumbel Distributions in the Upper Thames River Watershed under Global Climate Models" Department of Civil and Environmental Engineering, The University of Western Ontario, London, Ontario, Canada.

[25] Vogel, R.M. (1986). "The probability plot correlation coefficient test for the normal, lognormal, and Gumbel distributional hypotheses." Water Resources Research, Vol. 22, No. 4, pp. 587-590.

[26] Moriasi, D.N., Gitau, M.W., Pai, N., and Daggupati. P. (2015) Hydrologic and Water Quality Models: Performance Measures and Evaluation Criteria. Transactions of the American Society of Agricultural and Biological Engineers, Vol. 58(6): 1763-1785

[27] Masse, B. (2017). "Frequency Analysis and Plotting Positions", Leadership in Sustainable Infrastructure, HYD725-1 to HYD725-9.

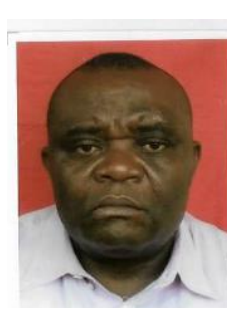

Dr. Ologhadien is an Associate Professor and formerly Acting Head, Department of Marine Engineering at the Rivers State University of Science and Technology, Port Harcourt. He graduated in 1988 with Bachelor of Technology (B. Tech) degree in Civil Engineering from the Rivers State University of Science and Technology, Port Harcourt, Nigeria. He received his $\mathrm{M}$. Eng and $\mathrm{PhD}$ degrees in 2003 and 2012, respectively in Civil Engineering from University of Port Harcourt, Nigeria. He also received a PGD in Hydraulic Engineering from IHE, Delft Netherlands in 1991. He has over 25 years of teaching, research and consultancy experience in Hydraulic engineering, Water resources Engineering, River and Coastal engineering. Dr. Ologhadien has authored several publications in peer- review journals and over 100 technical reports to his credit.

Dr. Ologhadien is professional engineer registered with the Council for the Regulation of Engineering in Nigeria (COREN-R9516), a corporate member of the Nigerian Society of Engineers (R07389) and the International Association of Hydraulic Research (I-7512). He is also a recipient of two fellowships from the Netherlands Government in 1991 and 2003, respectively. 